\title{
Téoros
}

Revue de recherche en tourisme

\section{Fleuves, civilisations et tourisme}

\section{Normand Cazelais}

Volume 11, numéro 3, octobre 1992

Fleuves, civilisations et tourisme

URI : https://id.erudit.org/iderudit/1078033ar

DOI : https://doi.org/10.7202/1078033ar

Aller au sommaire du numéro

Éditeur(s)

Université du Québec à Montréal

ISSN

0712-8657 (imprimé)

1923-2705 (numérique)

Découvrir la revue

Citer cet article

Cazelais, N. (1992). Fleuves, civilisations et tourisme. Téoros, 11(3), 3-4.

https://doi.org/10.7202/1078033ar d'utilisation que vous pouvez consulter en ligne.

https://apropos.erudit.org/fr/usagers/politique-dutilisation/ 


\title{
Fleuves, civilisations et tourisme
}

\author{
Normand Cazelais
}

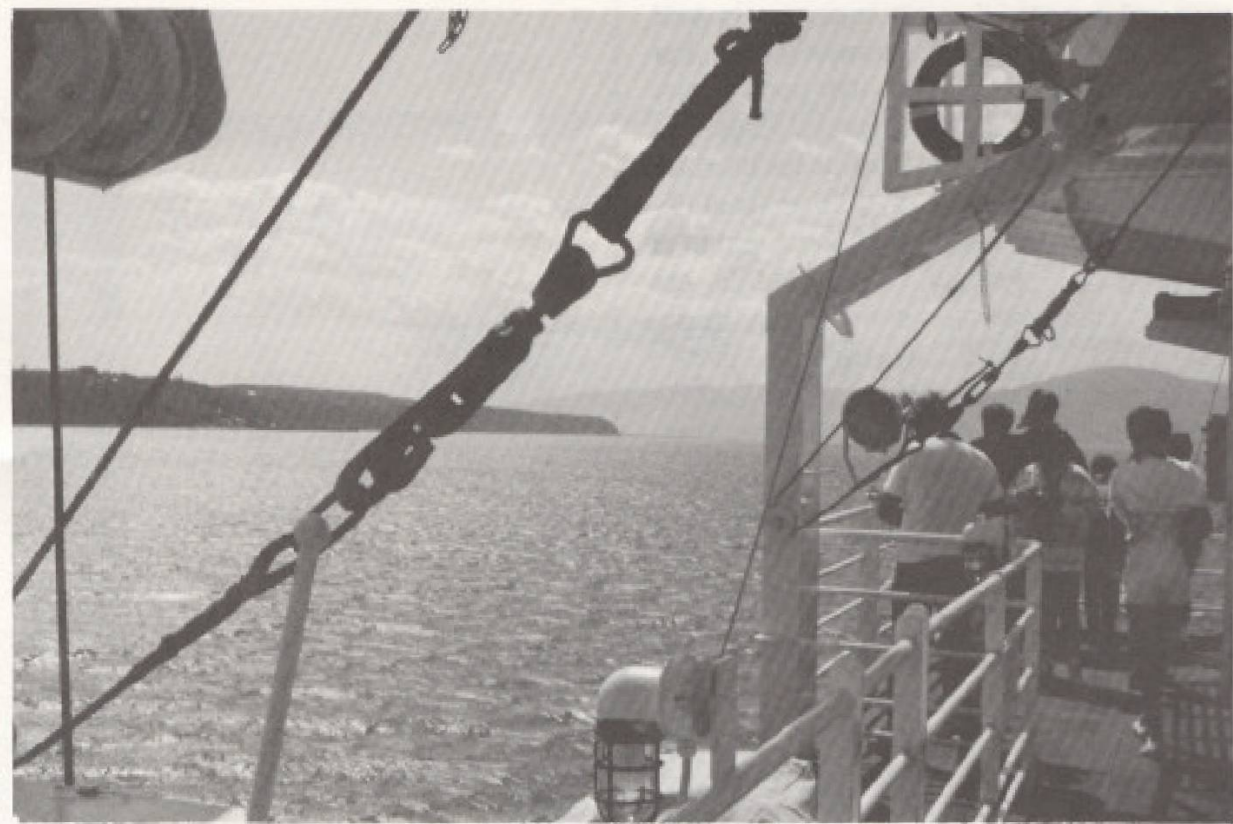

Les Indiens appelaient le SaintLaurent le chemin quimarche. La goutte d'eau allant du ciel à la mer.

Pour les anciens Égyptiens, le Nil était le Nahal, la rivière, sillon puissant, nourricier. indispensable, salvateur: la vie, la survie, au milieudu désert. Thèbes, Louxor, Memphis, Khartoum, toutes les capitales des Empires millénaires s'établirent sur ses rives. Au siècle dernier encore, les scientifiques de toute allégeance avaient peine à identifier avec précision ses origines, à remonter le Nil Bleu, puis le Nil Blanc, puis le Bahr-elGhazal, la rivière des Gazelles, jusqu'au lac Victoria, à 6671 kilomètres de l'extrémité du delta. Peine égalementà distinguer le mythe de la réalité.

Sur les eaux boueuses, peu profondes et souvent vagabondes du Mississipi au temps des crues, des bateaux à aubes, à fond plat et à hautes cheminées dentées, baptisés Delta Queen ou Mississipi Queen, noyés de touris-

Monsieur Normand Cazelais est chroniqueur en tourisme et conseiller a la vice-présidence-Environnement de l'Hydro-Québec. tes en mal d'exotisme ou de nostalgie, reprennent le va-et-vient des paddle-boats d'autrefois qui remontaient coton et matières premières, jazz et négritude vers l'Ohio, le Missouri et les grands centres urbains du Middle West, et descendaient vers le Sud, au coeur de ce qui fut l'immense Louisiane calquée sur tout le bassin versant du grand fleuve, les produits ouvrés et autres fruits de l'hégémonie du Nord.

A travers les siecles, les fleuves furent axes de communication et de circulation, outils de négoce, d'activités portuaires, d'industrialisation, de développement urbain. Autrement dit, d'inépuisables agents de civilisation.

Dans le hall d'un grand hôtel sur le Danube a Budapest trône une maquette du Széchenyi, vapeur ă aubes qui en fréquentait les eaux au siècle dernier. Creuset de l'âme slave, artère des mystères et des espoirs de la Mittle Europa, ponctué de canaux et centrales hydroélectriques, navigable malgré les obstacles naturels, fleuve unificateur, le Danube a favorisé le commerce, les échanges, la migration des idées et des influences. A travers les âges, hommes, sociétés et États ont édifié sur ses berges Ratisbonne, Vienne,
Bratislava, Budapest, Prague, Belgrade et autres villes-phares.

Le Rhin coule des Alpes suisses vers les rives deFrance, vers I' ljseletpolder duZ Zuydersee, vers le delta néerlandais, le Lek et Rotterdam, plus grand port du monde. En Allemagne, il s"enfonce profondément dans le massif schisteux. Au long de cette Trouée hérö̈que, les inversions de température sont fréquentes et développent des nappes de brume traîtresses pour les navigateurs. Mais l'imagination humaine a trouvé mieux que les lois de la météorologie. À un coude du Rhin, un cap de près de deux cents mètres élève sa muraille et oblige des manoeuvres délicates qui ont résultế en de nombreux naufrages. Paysage le plus photographié d'Allemagne, figurant sur un nombre incalculable de posters touristiques, ce rocher s'appelle la Lorelei et le chant envoûtant de cette sirène a attiré des générations de bateliers à se fracasser à ses pieds. Ainsi veut la légende. C'est de ce fleuve aussi que fut tiré le trésor des Ondines, l'Or du Rhin, dont fut forgé l'anneau devant assurer la domination du monde par la tyrannie du précieux métal. Et qui inspira, bien entendu, la tétralogie de Wagner.

Anton Tchéckov, illustre dramaturge et prosateur russe, en route vers l'extrémité de la Sibérie et le Pacifique, vers l'île de Sakhaline où il ira soigner les prisonniers oubliés au fin fond de l'empire et attraper cette tuberculose qui lui rongera les poumons le reste de sa vie, raconte dans ses lettres à sa famille et ses amis, ses croisières sur la Léna et l'Ienisseì. Il narre avec émotion les sentiments qu'il a éprouvés sur les eaux de ces fleuves interminables qui cisaillent de sud en nord la steppe sibérienne, à contre-courant des mouvements des hommes qui les portent d'ouest en est et vice-versa. Plus au sud, encore aujourd' hui, malgré les récentes vicissitudes de l'économie politique soviétique, des naviresde croisière, chargés à plein bord, transportent leurs flots de touristes sur la Volga, au coeur même de la Russie millénaire.

Petit cours d'eau mais grand fleuve est the ThamesRiver: àpeine 338 kilomètres depuis ses origines dans les collines des Cotswold 
jusqu'à son embouchure dans la mer du Nord. Pourtant, le nombril du monde, point de référence de tous les navigateurs maritimes et fluviaux de la planète, se trouve à Londres sur la rive droite de la Tamise: le méridien d'origine, le point zéro de longitude passe par l'observatoire de Greenwich fondé par Charles II en 1675. Espèce de miracle moderne, les eaux du fleuve ne sont plus glauques, sales etinqualifiables, comme elles le furent trop longtemps. Aupied de Big Ben qui Égrène le temps, des pêcheurs tendent leurs lignes, prennent des saunons et mangent sans crainte leurs prises. Et, le soir, des bateaux-mouches promènent leurs passagers devant la City toute illuminée.

Fleuves et peuples, cultures et civilisation. Fleuves et tourisme. La-bas, dans le souscontinent indien, le Gange est un fleuve sacré, bras purificateur des dieux à la portée des hommes, et de partout les croyants font vers Bénarès, la ville sainte, le pèlerinage de toute une vie, $y$ laver leurs fautes et renaitre à la destinée. Au fond des gorgesdu Colorado, entre ces murailles de pierre que les Américains appelle Corridors of Time, des gens de tout âge, venus à grands frais, casqués, ceinturés, embarqués dans des dinghys sur l'écume coléreuse du fleuve, retrouvent - ou, du moins, croient le faire - les exaltations des premiers explorateurs confrontés aux aleas de l'aventure et de l'inconnu.

Tous dans l'histoire humaine, marchands, militaires, découvreurs, missionnaires et pèlerins, poètes et gens de science, voyageurs de tout motif, ont suivi les fleuves pour relier les horizons des mers et les profondeurs des continents, Ils ont reconnu leurs confluences, établi des postes d'échanges, édifié ports, ponts et entrepôts, bâti villes et forteresses, cathédrales et palais, laissé souvenirs et traces de leurs passages et activités. Par les fleuves, ils ont appris la géographie des espaces à occuper, à maîtriser, à développer.

Aux levres de l'A Alantique, entre les bouches de I'Amazone, fleuve démesuré, et du Tocantins, autre fleuve arrivé à l'océan après plus de 2500 kilomètres depuis le plateau des Goias, est née du limon sans cesse charroyé, sous le feu de l'Équateur, l'île de Marajo. Nappée de prairies et de marécages, peuplée de hordes de buffles et d'à peine 30000 habitants, régulièrement inondée, elle couvre $52800 \mathrm{~km}^{2}$, un territoire $20 \%$ plus grand que la Suisse... Le Saint-Laurent lui-même, auquel Téoros a consacré un numéroen juillet 1987 (vol. 6, no 2), oblige les géographes à repenser leur vocabulaire: où commence le fleuve? Où finit la mer? La zone désignée de l'estuaire est-elle bien nommée? Ne commencerait-elle pas plus en amont? Et que seraient le Québec, sa population et sa société sansce fleuve agéants, comme le chante l'hymne national?

Les fleuves fascinent l'imaginaire des hommes. Au cours des générations, ils sont devenus des attractions touristiques. Par millions, les gens se déplacent pour y faire des croisières ou en découvrir les rives. Ou les especes qui y vivent, comme les baleines et bélugas par exemple dont ils peuvent observer les ebats au droit du Saint-Laurent et du fjord du Saguenay. Mais sont-ils, ces fleuves, aussi connus et appréciés qu'ils devraient l'être? Au-delà des forfaits, des croisières, des plages, des paysages, des circuits riverains, leurs potentiels touristiques sontils exploités à leur juste mesure?

Avec le temps malheureusement, les grands fleuves ont connu les affres de la pollution. Les effets de la vie moderne sont tels que ces géants fragilessonten gravedanger. Eflluents et dépôts toxiques, déversement d'hydrocarbures, d'agents chimiques et d'eaux usées, érosion et alluvionnements accélérés, conflits d'usages, implantations et développements desordonnéset incontrôles de fonctions agressives, dévoreuses d'espace (industries, ports, airesrésidentielles, commerciales, etc.) attaquent sans cesse leur santé, menacent leur vie et leur survie.

Toute civilisation est le fruit du développement d'une pensée collective, d'une harmonie entre les sociétés et leurs milieux naturels. Civilisation et environnement $s^{*}$ alimentent et se répondent. A leur convergence, le tourisme peut faire oeuvre utile, notamment dans le cas des fleuves, grands et petits. Pour en mettre en valeur les ressources touristiques, il faut des fleuves en santé. Et le tourisme, en mettant les fleuves à la portée des hommes, peutactivement favoriser l'émergence d'un désir plus grand et plus universel de les voir en bonne santé et connâtre vraiment un développement durable. 